\title{
Robotics: development factor or social isolation of the child
}

\author{
Irina Kulikovskaya ${ }^{1 *}$, Raisa Chumicheva ${ }^{1}$, and Ivan Panov ${ }^{2}$ \\ ${ }^{1}$ South Federal University 344006, Rostov-on-Don, Russia \\ ${ }^{2}$ MBDOU № 312, 344093Rostov-on-Don, Russia
}

\begin{abstract}
In this article, dealing with robotics is defined as a factor driving the development of preschool children. What was created by science fiction writers has become a natural space for the child. Children do not know a world where there are no drones, smart phones, and computers. Robotics is becoming one of the leading activities for children, which determines the development of creativity, initiative, and independence. Joint design acts as a team work environment where children learn to agree on a project topic, discuss problems in its implementation, look for information from different sources, and use digital technologies. However, immersing a child into the world of robotics can isolate him from the society; immerse him into the virtual world. "Digital flashing" of a child's brain can affect its cognitive methods, affecting the neural mechanisms responsible for communicating with other people. This problem is being studied by scientists from around the world. Today the world is doubling - life in two spaces - material, objective and virtual, ideal. That is why the determination of the common ground for these worlds determines the harmonization of the children development in modern space. One of this common ground could be robotics classes. In preschool education, the development of technical creativity occurs through the designers of LegoEdu. The logic of designing cognitiveresearch activities of children is presented.
\end{abstract}

\section{Introduction}

The world in which modern children live is filled with various technical devices household (home appliances), entertainment (game consoles, tablets, etc.), industrial (devices for building, repair, etc.), medical (research devices activities of organs and systems of the body, biotechnology), research (computing devices and tools). The challenge for a child entering the techno world is more relevant than ever, since robots are no longer something fantastic, but are in direct contact with humans. At various times, such scientists and philosophers as M.I. Makarov, S.L. Zenkevich, O.A. Tyagunov, V.V. Tarapata, Yu.I. Topcheev, K. Fu, R. Gonzalez, N. Braga, V. G. Bykov, R. M. Luchin, I. V. Tuzikova, S. A. Filippov, K. Schwab, A. S. Yushchenko and others studied the issue. Turning to the future,

\footnotetext{
* Corresponding author: iekulikovskaya@sfedu.ru
} 
where human-robot interaction will become a natural phenomenon, was the thought subject of world famous writers - A. Azimov, R. Heinlein, S. Lem, D. Adams and many others. The urgency of the robotics problem is enhanced by the fact that it is attractive for its unusualness, originality, stimulates the child to interact with it, giving rise to a new problem of his social self-isolation.

\section{Problem formulation}

In the process of studying this problem, the team of authors posed a number of tasks:

1. To actualize the problem of robotics in the system of preschool education, to study the degree of its development in modern pedagogical research.

2. To identify the pedagogical developing potential of robotics in the cognitive development of the child and his research activities.

3. To identify the pedagogical risks of social self-isolation of the child in the process of robotic design.

\section{Research methods}

Theoretical systematic comparative analysis of scientific literature over the past 5 years, content analysis of scientific literature, analysis of products of children's constructive activities are used.

\section{Cases of educational robotics}

\section{Case 1. Robotics as a scientific problem and a means for a child's development}

Educational robotics is an interdisciplinary phenomenon combining such fields as physics, mechatronics, mathematics, cybernetics, etc. In education, robotics ceases to be in the status of innovation. The child lives in a rapidly changing world where the robot occupies its unique place, acting as a car driver, a seller in a store or cafe, a surgeon, etc. Robots are increasingly becoming part of everyday life; cheap sensors, powerful computers, artificial intelligence programs make them more independent. They help people by replacing them, transforming healthcare and caring for the elderly. Robotics provides a change in the status of engineering professions [6]. The subjectivity of the child manifests itself in the fact that he independently discovers a problem (game), takes the initiative in solving it, and embodies his plan.

Robotics is becoming a factor in the development of children, as they can not only participate in solving those issues, topics and problems that adults formulate, but also offer their own, interesting questions, topics and forms of work for them. Activities with different objects provide the child with the development of cognitive competencies and the ability to independently learn the meaning of objects and the interdependence between them, which determines the development of mental actions - comparison, analysis, inference, and conclusions. In an ever-changing world, it is necessary to teach children to cope with unexpected situations and solve problems that they have not encountered before. We can only guess what professions will be in demand in the future, but we know for sure that emotional self-control, the ability to think positively, the realization of creative energy, the willingness to adapt to constantly changing living conditions and learn all life will remain significant, as well as a creative economy based on integration of intellectual capital and creativity (STEAM-competence) [12]. The abbreviation STEAM is deciphered as follows: $\mathrm{S}$ - natural sciences (science), $\mathrm{T}$ - technology (technology), $\mathrm{E}$ - engineering (engineering), A - art (art), M - mathematics (mathematics). These are human competences 
of the XXI century, which must be developed in children, using the resources of activities that are of interest to them. Unmatched interest in most is caused by robotics, games with robots and designers, for example, LEGO Education designers, which are designed for preschool children.

However, robots and computer games can act as a factor in the social isolation of the child. The lack of mutual understanding with adults, the child being 'unnecessary' determines the immersion in the virtual world, hiding from the frightening reality. Speaking about social isolation, scientists emphasize that this condition of a person causes his suffering, a sense of insecurity, and fear of the outside world (K. Rubin, 1993). Partial or complete refusal to communicate with peers and adults, weakening of emotional reactions, narrowing of the sphere of interests are the consequences of the child's social isolation. Robots are interesting in themselves - as partners in interaction and games. Being in the virtual space, the child "falls out" of reality. He has virtual friends and heroes. Spending a lot of time in this world, he satisfies his needs for interaction and mutual understanding.

\section{Case 2. Challenges of Robotics in Modern Preschool Education}

Robotics has a wide range of applications in the system of preschool education: as a means of personality development in the educational mode (learning in the game) initiative and independence, communication methods, constructive, research skills.

Work on robotics begins long before the child connects his mechanism to the USB port, his mechanism begins to move in the direction he sets and make the sounds the creator needs. It begins with the task of a teacher for a group of 3-year-old children in combining two or more details to create something new. Preschool years are very important for socialization, learning about the world by children, and acquiring ways to discover something new, since it was at this time that the development of their abilities was much faster and more intense than in any other period of life $[8,9,10]$.

The prerequisites for the development of robotics are the psychological characteristics of the child - curiosity development, the need to learn new things, to experiment, to find answers to the questions that underlie the future successes of the child in the study of mathematics, technology, physics, engineering design, and even the fine arts.

The social and communicative development of children by means of LEGO games is determined by joint design, the development of non-standard solutions due to the development of the plot, positive attitudes towards interaction, and the importance of safe behavior in games. Communications on a variety of occasions, in particular, on the role of robots in modern life, contribute to the development of children's social and emotional intelligence. Such philosophical dialogues require teachers to pay attention to the children's way of thinking, expressing their emotions and feelings, and open up unusual interpretations of future scenarios. Children are interested in communicating with each other and adults, pondering the idea of a robot that performs actions inherent in people. Kids become more confident when they start to express their thoughts, and the moderator teacher supports the thinking process ("Have you expressed an interesting thought, does anyone have other ideas?", "But how can I say it differently?", "Oh, this thought sounds great. Can I see it from the other side?" "Are there any other solutions?"), Contributing to the social and communicative development of children. Designer LEGO DUPLO provides the emotional development of kids from 3 years. Cognitive development in the process of engaging in robotics is associated with the discovery of various spheres of life - urban, outer space, the life of wild and domestic animals, the world of professions, etc. The absence of emotionally negative assessments and constant indications of errors in the design process become the motivators that captivate children. For example, the LEGO Education "STEAM Planet" set in a playful way develops children's natural curiosity about the principles of gears, movement and measurements, etc. 
LEGO WeDo ensures the achievement of the Federal Governmental Standard of Preschool Education targets: development of initiative and independence; teaches to model; develops engineering competencies, stimulates research activities, etc. Thanks to the designer, the speech development of children occurs. Several children can get involved in the game at once: they design, discuss ideas and roles together, think and communicate with the help of elements acting as a means of forming respect for the opinions and contributions of other participants. They are looking for different options for solving the tasks, learn to understand how different solutions are applied in practice, program and design their own robots. Science becomes a holiday, captivates and fascinates children. Young children, playing in Lotto LEGO DUPLO, learn the names of animals, their cubs, parts of their bodies, behavior patterns. This game also develops mindfulness, design abilities and fine motor skills. Kids remember colors, get acquainted with geometric shapes, learn how to analyze and work according to a pattern, to develop communication skills, playing in turn, to negotiate and share the results. They can interact in pairs, teams, subgroups.

Artistic and aesthetic development through LEGO designers is due to bright, colorful images. Through various elements, children learn to create ornaments, different designs urban, suburban landscapes, to equip home space. Realizing original ideas, little builders develop constructive thinking, an aesthetic attitude to the world, and creative projects are being implemented. Colorful "bricks" are a fascinating tool for the productive development of creative skills in preschool children.

\section{Case 3. Robotic engineering: the social position of the child in it}

The designer sets of LEGO Education have become a means for children to express their own role in the peer community. The child's social position represents his place, position in the group, regulating behavior, helping or limiting opportunities to realize fantasies, be creative and create his own project. Robotic engineering as a cultural practice becomes a unique source of optimizing the social positions of children, the manifestation of each as a leader in any activity. Materials help them improve their knowledge; activate communication, as children always enthusiastically describe the results of their creative activity. The development of speech, cognitive, creative, artistic and aesthetic development in unity stimulates the joint activity of children who intuitively compose stories, adding unique details to the overall end result. Children are provided with unlimited opportunities for research, so they realize that for creativity there are no limits in self-expression with the help of a designer, they realize incredible ideas ("City residents of LEGO DUPLO." All the characters are dressed in clothing or uniforms corresponding to their profession). This constructor allows you to explore situations like "What happens if? ..", "How to do that? ..", etc. Joint thinking over possible options for the development of the plot determines a positive change in the social positions of children.

\section{Conclusion}

Robotics in preschool education is not only a way of introducing a child to modern trends in society, science, culture, but also an excellent tool for the development of children, their social and STEAM competencies. These competencies provide children with the opportunity to participate in team projects, express their opinions taking into account the creative environment, perceive and focus on constructive criticism, and carry out selfpresentations. Modern didactic tools, such as LEGO Education, cultivate and develop such abilities of children.

Classes in robotics ensure the holistic development of children - their playful, communicative, cognitive-research, constructive, aesthetic activities. Investigations of objects in the surrounding world and experimenting with them are significant for modern 
children, for their possible future technical education. In the context of civilization development, mastery of the basics of robotics acquires special significance. We are surrounded by mechanisms without which it is impossible to imagine everyday life: talking navigators; voice applications that easily answer any question; interactive toys that remember the owner's habits and enter into communication with him; a robot vacuum cleaner that allows the child to understand who is responsible for cleanliness in the house, etc. For modern children, a fascination with technology does not mean the ability to engineering and exact sciences. Today, technology is becoming an area of life in which the adherents of the exact sciences and the humanities must be competent. The task of the education system is to provide the child with a relevant set of competencies corresponding to the real spirit of the times, in which robots are not the future, but the present.

\section{References}

1. Sberknoledge, 8, 3-10 (2017).

2. D. Markoff, Homo roboticus, LLC “Alpina non-fiction”, (2017).

3. Information on www.2045.ru/manifest.

4. I.V. Ladygina, Social and Ethical Problems of Robotics, Bulletin of Vyatka State University, 30 (2017).

5. V.V. Tarapata, Five lessons in robotics, Informatics-First of September 2014, 11, $12-$ 25 (2014).

6. I.V. Tuzikova, The study of robotics - the path to engineering specialties, School and production, 46 (2013).

7. K. Schwab, The Fourth Industrial Revolution (Eksmo, 2016).

8. Lego "More than a Cube" (Base Edition 2017).

9. I.E. Kulikovskaya, Theory of Personal World Outlook Evolution: Categories, Provisions, Proofs, Middle East Journal of Scientific Research, 15(5), 698-706 (2013) DOI: 10.5829 / idosi.mejsr.2013.15.5.11320

10. M. Rollins, LEGO technic robotics [Electronic resource]: design and build custom LEGO bots with LEGO technic, (New York, NY: Apress, 2013). (Technology in Action). Information on http://link.springer.com/book/10.1007\%2F978-1-4302-4981-8.

11. The Robotics Divide. A New Frontier in the 21st Century?, ed. A. L. Peláez (Springer-Verl., London, 2014). Information on https://link.springer.com/book/10.1007\%2F978-1-4471-5358-0.

12. A.V. Frolov, Reform of the US Innovation System: from STEM to STEAM Education, Alma mater (Bulletin of Higher Education), 9, 101-105 (2013).

13. K.H. Rubin, J.B. Asendorpf, N.J. Hillsdale, Social withdrawal, inhibition and shyness in childhood (Lawrence Erlbaum Ass., 1993). 